\title{
Studies of the Association of Dyes with Surfactants in Aqueous Solutions: Spectrophotometry and Computer Simulation
}

\author{
Serghey A. Shapovalov*, Vadim K. Ponomariov, Oryna V. Mosharenkova, Sophia V. Butenko \\ Research Institute of Chemistry, V. N. Karazin Kharkiv National University, \\ Svobody sq.4, Kharkiv, 61022, Ukraine \\ serghey.a.shapovalov@,karazin.ua
}

Keywords: association, aqueous solutions, dyes, enthalpy of formation, spectroscopy, surfactants, semiempirical methods.

The association of cationic dye (pinacyanol, PC) with anionic dyes (ethyleosin, EE, or rhodamine $200 \mathrm{C}, \mathrm{R} 200 \mathrm{C}$ ), and also the interaction "dye+surfactant" has been investigated in aqueous solutions by visible spectroscopy and computer simulation. Cetylpyridinium bromide (CPB), sodium dodecylsulfate (SDS) and triton X-100 (TX) were used as cationic, anionic and non-ionic surfactants respectively. The formation of "dye+surfactant" associates takes place at low dye concentrations $\left(\geq 10^{-6} \mathrm{M}\right)$ and concentrations of surfactant, which are much smaller than the critical micelle concentrations $(\mathrm{CMC})$. In contrast, similar concentrations $\left(10^{-6}-10^{-4} \mathrm{M}\right)$ of small cations of tetramethylammonium or tetraethylammonium have no noticeable effect on the absorption spectra of the dye in the "dye+tetraalkylammonium salt" systems; it indicates the absence of formation of new compound between the dye and salt. The standard enthalpy of formation of "dye+dye" or "dye+surfactant" associates has been determined by AM1 and PM3 semiempirical methods. The computer simulation confirms that the formation of these associates is energetically beneficial.

\section{Introduction}

Recently, the development of spectralluminescent methods initiated the systematic studies of the association phenomenon involving dyes in solutions [1-13]. Such association is instrumentally fixed at relatively low molar concentrations of particles (from of $10^{-7}$ to $\left.10^{-5} \mathrm{M}\right) \quad[1,3-5,10,13,14]$. Spectroscopic methods are in general highly sensitive and reasonable for the studying under small concentrations. The absorption UV/Vis spectroscopy is one of the most suitable methods for quantitative studying the association process of dyes in solution. Notice, that "organic dye + surfactant" systems are widely investigated in photometric and luminescence analysis; they are being studied for dyes with developed $\pi$-electronic fragments such as phthaleines, cyanines, porphyrins, oxazines, azo-dyes. Current research are related to biomolecular systems (modification of DNA and polypeptides, polyintercalation and 
aggregation of supramolecular structures), quantitative determination of components of pharmaceutical preparations, and chemical analysis of surfactants also $[1,2,5,7,10]$. Some publications $[2,5,8,12,13]$ deal with thermodynamics and the manifestation of various types of interactions in such multiatomic systems.

This paper discusses the association of cationic dye (pinacyanol, PC) with anionic dyes (ethyleosin, EE, or rhodamine 200 C, R200C), and also the interaction PC, EE, R200C with surfactants. Cetylpyridinium bromide (CPB), sodium dodecylsulfate (SDS) and triton X-100 (TX) were used as cationic, anionic and nonionic surfactants respectively. The purpose of the investigation was spectrophotometric study of interactions between polyatomic particles at low $\left(10^{-6}-10^{-4} \mathrm{M}\right)$ concentrations in aqueous solutions and the estimation of energy (the standard enthalpy of formation) of associative particles. It should be noted, that the solution of such problems is a physico-chemical basis for the practical application of the properties of the indicated systems in various fields, such as analytical chemistry (quantitative determination of metals or surfactants, aromatics and their derivatives [15]), physical chemistry (determination of the critical micelle concentrations, CMC [16-18]), pharmaceutical chemistry and biochemistry (DNA modification, chemical analysis of drug components [19-23]). Interactions between dye and surfactant or between an associate of two dyes and surfactant have growing interest in terms of creating methods for the determination of various substances in solutions [1, 12].

\section{Experimental part}

Chemical preparations of R200C

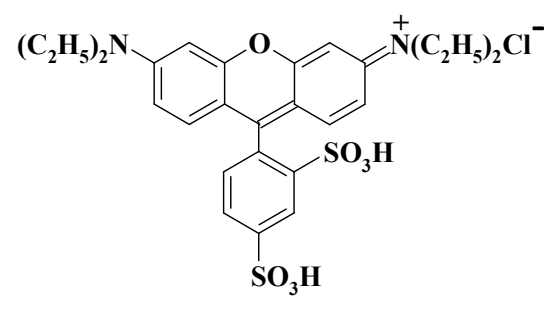
EE<smiles>CCOC(=O)c1ccccc1-c1c2cc(Br)c(=O)c(Br)c-2oc2c(Br)c(O)c(Br)cc12</smiles><smiles>CCCN1/C(=C/C=C/c2ccc3ccccc3[n+]2CC)C=Cc2ccccc21</smiles>

and PC

were the trademark "Sigma" with 95\% content of the main substance. The chemical purity of the dyes was checked by spectrophotometrically using known values of the molar extinction coefficient [1]. Mass fraction of chlorides of alkylammonium salts and preparations of CPB, SDS, TX was not less than 90\%. Absorption spectra were measured on "Hitachi U-2000" and on modernized spectrophotometer "SF-46" at $1 \mathrm{~cm}$ thickness of a light absorbing layer and a temperature of $298 \mathrm{~K}$.

Methods of molecular mechanics (MM+, AMBER) and semiempirical quantum chemical methods (AM1, PM3) are used to estimate the thermodynamic properties and to identify the 
most probable structure of associates. The corresponding simulations were performed in the HyperChem software package [24]. The method of MM+ was used for "vacuum" case and AMBER was used for "Periodic Box function" in water). At first, the optimization of the geometry of structures was carried out, and then, the values of the standard enthalpy of the associates were determined by semiempirical methods.

Note, that the use of nonempirical methods, for example, Hartree-Fock, implies the necessity to specify nuclear coordinates of the molecule and the number of electrons and to choose the basis set of the calculation. The AM1 and PM3 methods work much more rapidly than the nonempirical methods and they give more reliable results as to values of standard enthalpy of formation. Their principal distinction from the nonempirical methods is the complete or partial rejection of calculations of one- and two-electron integrals appearing in the HartreeFock method. The approximate operator, whose elements are obtained from empirical data, is used instead of the precise operator. The differences in methods of choosing parameters, which are selected for both particular atoms and their pairs, and the introduction of various approximations (the approximation of zero-point differential overlapping is introduced for two-electron Coulomb and exchange integrals; only valent electrons are considered: it is believed that electrons of atomic cages only screen nuclei; only atomic orbitals with the principal quantum number corresponding to the highest electron-occupied orbitals of isolated atoms (minimal basis set) are taken into account in molecular orbitals, and several others) resulted in the creation of calculated modifications [24, 25]. The AM1 and PM3 methods take into account a considerably greater number of parameters than other methods consider (for AM1 the parameters were optimized over 100 molecules, from 7 to 21 parameter per element; for PM3, over 657 molecules, 18 parameters per element) [24]. So, the parameters of the AM1 and PM3 methods reproduce to values of the standard enthalpy of formation in the best way. The use of semiempirical methods is due to the fact that even for small molecules nonempirical calculations lead to errors in the values of the standard enthalpy of formation exceeding $25 \mathrm{kcal} / \mathrm{mol}$. This is due to the incompleteness of the used basis and the neglect of the energy of the electronic correlation. The errors inevitably increase in nonempirical calculated values and it acquire a systematic disposition with the increase of the size of a molecule [25]. Note, that the use of two methods is related not only to the tendency to assess the higher reliability in absolute values of standard enthalpy of formation, but also to minimize the systematic error in the discovery of the change in for associates of similar composition. 
The standard enthalpy of formation of associate $\left(\mathrm{dH}_{\mathrm{Cacl}}\right)$, each of molecule $\left(\mathrm{dH}_{\mathrm{Mol}}\right.$, $\mathrm{dH}_{\mathrm{Mol} 2}$ ) and the difference between the total enthalpy of the formation of molecules and the enthalpy of the formation of associate have been determined; this difference can be represented as $\Delta \mathrm{dH}=\mathrm{dH}_{\text {Mol1 }}+\mathrm{dH}_{\mathrm{Mol} 2}-\mathrm{dH}_{\text {Cacl. }}$ The optimal values of the RMS (root mean square) gradient were determined by additional measurements (RMS gradient is convergence gradient, $\mathrm{kkal} / \mathrm{mol}$; it is the rate of energy change (first derivative) with the change of the location of each atom of the structure in three mutually perpendicular directions is determined by separate experiments; the local minimum of the energy of the structure is considered to be achieved if its value becomes zero). RMS gradient was set to 0.005 under determining the optimal geometry of structures for systems in a vacuum and it equals to 0.1 in cases of water box. However, the RMS gradient was 0,1 for a vacuum and 1.0 for solvent systems in semiempirical methods. Such values are due to the fact that changes in the total energy of the system (E) or $\mathrm{dH}_{\text {Cacl }}$ become negligible with further reduction of the RMS gradient (the examples are given in Tables 1 and Tables 2).

Table 1. Dependence of the total energy E ( $\mathrm{kcal} / \mathrm{mol})$ on the value of the RMS gradient

\begin{tabular}{|c|c|c|c|}
\hline \multirow{2}{*}{ RMS } & \multicolumn{3}{|c|}{ System (method) } \\
\cline { 2 - 4 } & $\begin{array}{c}\text { R200C } \\
(\mathrm{MM}+)\end{array}$ & $\begin{array}{c}\mathrm{R} 200 \mathrm{C}+\mathrm{H}_{2} \mathrm{O} \\
(\mathrm{AMBER})\end{array}$ & $\begin{array}{c}\text { R200C- } \\
\text { EE+ } \mathrm{H}_{2} \mathrm{O} \\
(\text { AMBER) }\end{array}$ \\
\hline 2 & 43.8 & -119.9 & -692.2 \\
\hline
\end{tabular}

\begin{tabular}{|c|c|c|c|}
\hline 1 & 42.5 & -126.1 & -755.5 \\
\hline 0.5 & 42.2 & -158.2 & -762.1 \\
\hline 0.1 & 41.6 & -160.3 & -831.7 \\
\hline 0.05 & 41.5 & -160.3 & -831.7 \\
\hline 0.01 & 41.5 & -160.3 & -831.7 \\
\hline 0.005 & 41.5 & -160.3 & -831.7 \\
\hline
\end{tabular}

Table 2. Dependence of the total energy E ( $\mathrm{kcal} / \mathrm{mol})$ on the value of the RMS gradient

\begin{tabular}{|c|c|c|c|}
\hline \multirow{2}{*}{ RMS } & \multicolumn{3}{|c|}{ System (method) } \\
\cline { 2 - 4 } & $\begin{array}{c}\text { R200C } \\
\text { (PM3) }\end{array}$ & $\begin{array}{c}\text { R200C+H2O } \\
\text { (PM3) }\end{array}$ & $\begin{array}{c}\text { TX } \\
\text { (PM3) }\end{array}$ \\
\hline 2 & 246.1 & -204.8 & -408.1 \\
\hline 1 & 232.5 & -205.7 & -410.4 \\
\hline 0.5 & 232.6 & -210.3 & -414.2 \\
\hline 0.1 & 231.3 & -216.5 & -414.6 \\
\hline 0.05 & 231.5 & -224.0 & -415.3 \\
\hline 0.01 & 231.3 & $*$ & -415.5 \\
\hline 0.005 & 231.3 & $*$ & -415.6 \\
\hline 0.001 & 231.3 & $*$ & $*$ \\
\hline
\end{tabular}

(* It is inadequate calculation time under this value of RMS gradient, i.e., the "reasonable" number of cycles of successive calculated iterations is exceeded).

The Polak-Ribiere algorithm was used in all calculations (this algorithm is conjugate gradient method using one-dimensional searches). The obtained values do not exceed the errors of the calculation methods for determining the enthalpy of formation which is not better than $6 \mathrm{kcal} / \mathrm{mol}$ [24].

\section{Results and discussion}

Dye molecules exist as single-charge anions $\left(\mathrm{R}^{2} 200 \mathrm{C}^{-}\right.$and $\left.\mathrm{EE}^{-}\right)$or $\mathrm{PC}^{+}$cation in aqueous solutions according to the values of the decimal logarithms of equilibrium dissociation 
constant $\left(\mathrm{p} K_{\mathrm{a}}=0.08, \mathrm{p} K_{\mathrm{a}}=1.80\right.$ for equilibrium $\mathrm{HAn} \rightleftarrows \mathrm{H}^{+}+\mathrm{An}^{-}$, and $\mathrm{p} K_{\mathrm{a}}=3.5$ for equilibrium $\mathrm{HCt}^{2+} \rightleftarrows \mathrm{H}^{+}+\mathrm{Ct}^{+}$[1]). The cation-anionic interaction takes place at low dye concentrations $\left(\geq 10^{-6} \mathrm{M}\right)$ and leads to the formation of associates $\mathrm{Ct}^{+}+\mathrm{An}^{-} \rightleftarrows \mathrm{Ct}^{+} \cdot \mathrm{An}^{-}$. The degree of stability of these compounds is the value of the equilibrium association constant $K_{\mathrm{as}}$; this value is determined from the law of mass action as $K_{\mathrm{as}}=\left[\mathrm{Ct}^{+} \cdot \mathrm{An}^{-}\right] \cdot\left[\mathrm{Ct}^{+}\right]^{-1} \cdot\left[\mathrm{An}^{-}\right]^{-1}$, where equilibrium molar concentrations are indicated in square brackets. The numerical value of $K_{\text {as }}$ is actually thermodynamic at low ionic force of solution.

Cation $\left(\mathrm{PC}^{+}\right)$and anion $\left(\mathrm{R}^{2} 00 \mathrm{C}^{-}, \mathrm{EE}^{-}\right)$ interact with each other even at low concentrations $\left(10^{-6}-10^{-4} \mathrm{M}\right)$. On the contrast, cation-anionic interactions between $\mathrm{R}^{2} 00 \mathrm{C}^{-}$or $\mathrm{EE}^{-}$anions with alkylammonium cations are not typical. Figure 1 shows the absorption spectra of EE in the presence of tetramethylammonium (TMA) or tetraethylammonium (TEA) salts in solution.

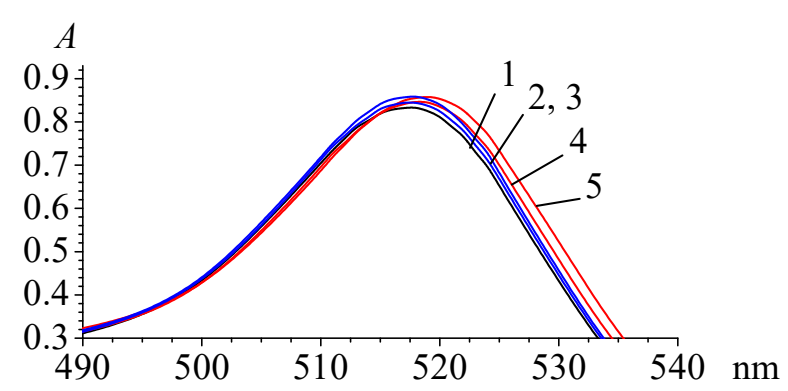

Figure 1. Absorption spectra of $\mathrm{EE}\left(\mathrm{c}=8.57 \cdot 10^{-6} \mathrm{M}\right)$ with the addition of TMA (spectrum 2, c $=0.05 \mathrm{M}$, and spectrum $3, \mathrm{c}=0.1 \mathrm{M}$ ) and TEA (spectrum $4, \mathrm{c}=0.05 \mathrm{M}$ and spectrum $5, \mathrm{c}=0.1 \mathrm{M})$.
It can be seen from absorption spectra that the addition of salts almost does not affect on the absorption spectra of a dye (spectrum 1) at $0.1 \mathrm{M}$ concentrations. It should be noted that a small bathochromic shift (3-4 $\mathrm{nm}$ ) of the maximum absorption when added to the TEA indicates the presence of a dye association even with such a small counterion (spherical radius is $3.5 \AA$ ). But this interaction is instrumentally fixed only at very high concentrations of TEA. Anionic dye R200C behaves similarly to these salts. Such spectral features indicate a weak association of polyatomic anions of dyes with small organic cations. Such weakly association is confirmed by calculations of thermodynamic data (see Table 3). These values correspond to the most thermodynamically favourable association structure (hereinafter the value of the global energy minimum, $\mathrm{kcal} / \mathrm{mol}$ ).

Table 3. Energy of "EE+alkylammonium salt" interaction

\begin{tabular}{|c|c|c|c|c|}
\hline \multirow{2}{*}{ Salt } & \multicolumn{2}{|c|}{ AM1 } & \multicolumn{2}{c|}{ PM3 } \\
\cline { 2 - 5 } & $\mathrm{dH}_{\text {Cacl }}$ & $\Delta \mathrm{dH}$ & $\mathrm{dH}_{\text {Cacl }}$ & $\Delta \mathrm{dH}$ \\
\hline TMA & -22 & 69 & -41 & 72 \\
\hline TEA & -33 & 58 & -54 & 60 \\
\hline
\end{tabular}

The interactions of dyes with surfactants were investigated for systems with differently charged components (e.g., $\mathrm{EE}^{-}$with a $\mathrm{CPB}^{+}$), and for a system with nonionic surfactants. The absorption spectra of the "EE+CPB" system are presented on the Figure 2. 


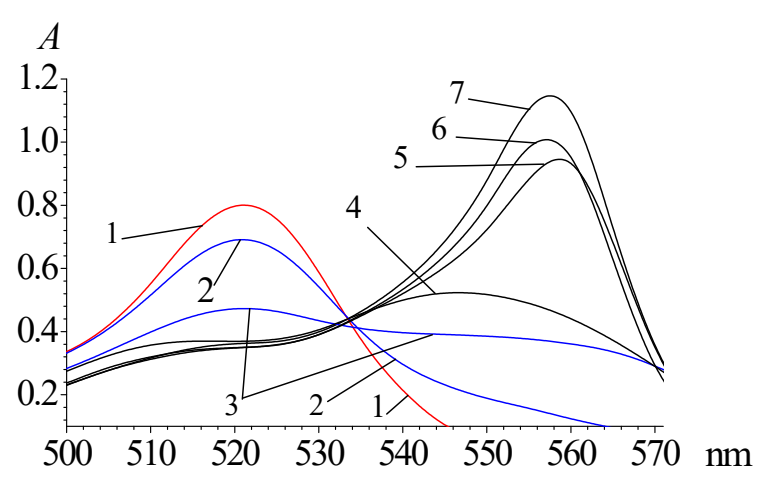

Figure 2. Absorption spectra of $\mathrm{EE}\left(\mathrm{c}=5.06 \cdot 10^{-6} \mathrm{M}\right)$ with the addition of CPB. c (CPB), M・10-4: $1-0 ; 2-$ $0.105 ; 3-0.314 ; 4-0.523-5.23 ; 5-10.5 ; 6-12.0 ; 7-$ 13.6 .

Spectra 2 and 3 indicate the formation of "EE $\cdot \mathrm{CPB}^{+"}$ associates in the before micellar region of surfactant concentration. In the micellar region (at the level of $\mathrm{CMC}=$ $\left.4.5 \cdot 10^{-4} \mathrm{M}[26]\right)$ the solubilization of the dye by micelles of surfactant is observed. It is reflected in spectra 4-7. These relief spectral changes indicate that such systems may have practical interest from the point of view of developing new spectral methods for determination of CMC for ionic surfactants $[17,18]$.

The "cationic PC+nonionic TX" system was also investigated to evaluate of the electrostatic component. The absorption spectra are shown on the Figure 3 for the "PC+TX" mixtures.

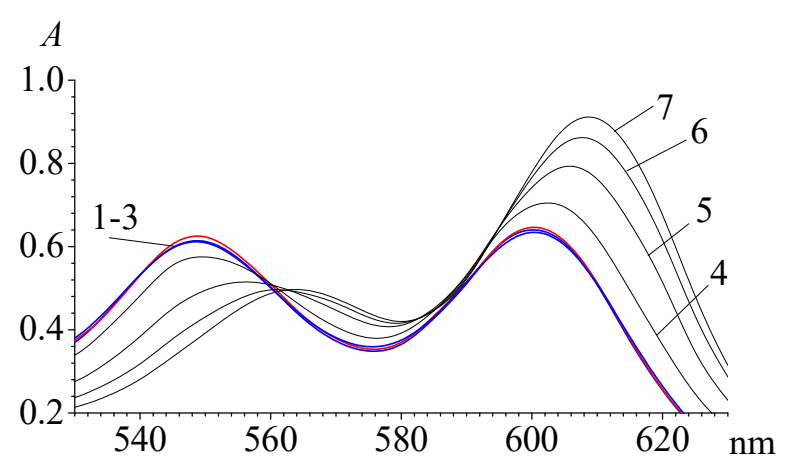

Figure 3. Absorption spectra of $\mathrm{PC}\left(\mathrm{c}=7.06 \cdot 10^{-6} \mathrm{M}\right)$ with the addition of TX. c (TX), M·10 $0^{-4}: 1-0 ; 2-0.6 ; 3$ $-2.01 ; 4-4.03 ; 5-6.04 ; 6-8.05 ; 7-10.1$.

Spectra 1-3 indicate that there are no interactions between the PC and TC at relatively small surfactant content in solution. However, spectral changes are detected at higher concentrations (spectra 4-7). Similar changes are characteristic in the micellar region of concentrations $\quad\left(\mathrm{CMC}=2.4 \cdot 10^{-4} \mathrm{M} \quad\right.$ [27] $)$. Restoring the contour of the absorption band of the dye and the bathochromic displacement indicates the solubilization of the dye by micelles [28]. It is noteworthy that spectral changes still take place in the absence of an explicit manifestation of non-specific (i.e., "cation + anion") interactions. The energy utility of the interactions between the cation of the dye and the nonionic surfactant is confirmed by the rather high values of $\Delta \mathrm{dH}$ in the water box (Table 4) for the four different initial variants of the mutual arrangement of the molecules. Note, that these values are essentially exaggerating the statistical error of the calculations.

Table 4. Energy of interactions " $\mathrm{PC}+\mathrm{TX}$ " with $\mathrm{H}_{2} \mathrm{O}$

\begin{tabular}{|c|c|c|c|c|}
\hline \multirow{2}{*}{ Variant } & \multicolumn{2}{|c|}{ AM1 } & \multicolumn{2}{c|}{ PM3 } \\
\cline { 2 - 5 } & $\mathrm{dH}_{\text {Cacl }}$ & $\Delta \mathrm{dH}$ & $\mathrm{dH}_{\text {Cacl }}$ & $\Delta \mathrm{dH}$ \\
\hline 1 & -7687 & 156 & -6719 & 275 \\
\hline 2 & -8092 & 561 & -7069 & 625 \\
\hline 3 & -7805 & 274 & -6825 & 381 \\
\hline 4 & -8109 & 578 & -7089 & 645 \\
\hline
\end{tabular}


Association at before micellar

Interaction between $\mathrm{PC}^{+}$and anionic SDS (Figure 4) are similar to the system "EE+CPB".

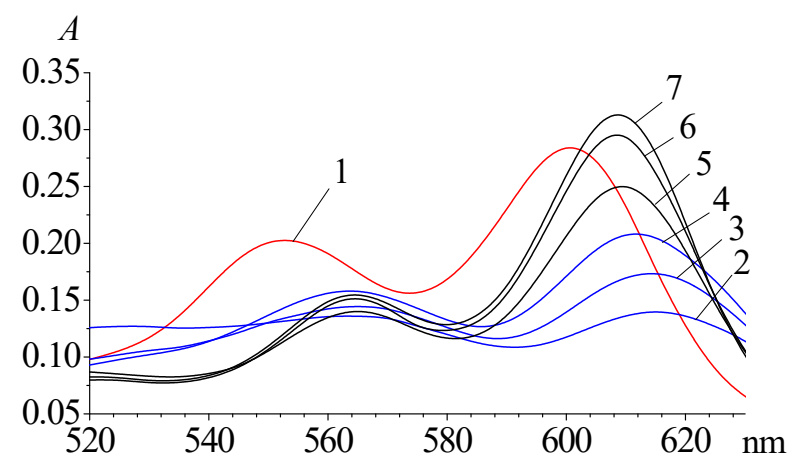

Figure 4. Absorption spectra of $\mathrm{PC}\left(\mathrm{c}=5,52 \cdot 10^{-6} \mathrm{M}\right)$ with the SDS additions. c (SDS), M·10-3: $1-0 ; 2-1.54$; $3-2.31 ; 4-3.07 ; 5-6.15 ; 6-7.69 ; 7-10.8$.

Such spectral changes also indicate the cation-anionic association (spectra 2-4). The solubilization of the dye by micelles takes place with subsequent increase of surfactant up to micellar concentration $\left(\mathrm{CMC}=8.5 \cdot 10^{-3} \mathrm{M}\right.$ [29]).

The results of computer simulation of this system show the thermodynamic utility (high values of $\Delta \mathrm{dH}$ ) of the interaction in vacuum (Table 5)

Table 5. Energy of "PC-SDS" interaction

\begin{tabular}{|c|c|c|c|c|}
\hline \multirow{2}{*}{ Variant } & \multicolumn{2}{|c|}{ AM1 } & \multicolumn{2}{c|}{ PM3 } \\
\cline { 2 - 5 } & $\mathrm{dH}_{\text {Cacl }}$ & $\Delta \mathrm{dH}$ & $\mathrm{dH}_{\text {Cacl }}$ & $\Delta \mathrm{dH}$ \\
\hline 1 & 242 & 317 & 172 & 275 \\
\hline 2 & 201 & 358 & 167 & 303 \\
\hline 3 & 244 & 315 & 170 & 300 \\
\hline 4 & 186 & 373 & 156 & 314 \\
\hline
\end{tabular}

concentrations of surfactant and typical changes with subsequent addition of surfactant) were also observed for the system "R200C+CPB".

On the basis of the results of the previous computer simulation for the study of the system "Dye1-Dye2-surfactant" it has been selected two such dyes and surfactants, so that the interaction of "Dye1-surfactant" was more thermodynamically profitable than "Dye1+Dye2" and, accordingly, was implemented in aqueous solutions. An analysis of the energy of intermolecular interactions (Table 4-6) leads to the conclusion that it is expedient to investigate the "PC+EE", "PC+TX", and "PC+SDS" systems.

Table 6. Energy of "PC-EE" interaction

\begin{tabular}{|c|c|c|c|c|}
\hline \multirow{2}{*}{ Variant } & \multicolumn{2}{|c|}{ AM1 } & \multicolumn{2}{c|}{ PM3 } \\
\cline { 2 - 5 } & $\mathrm{dH}_{\text {Cacl }}$ & $\Delta \mathrm{dH}$ & $\mathrm{dH}_{\text {Cacl }}$ & $\Delta \mathrm{dH}$ \\
\hline 1 & 306 & 207 & 257 & 161 \\
\hline 2 & 463 & 50 & 378 & 40 \\
\hline 3 & 439 & 74 & 374 & 44 \\
\hline 4 & 453 & 60 & 384 & 34 \\
\hline
\end{tabular}

It should be noted that the theoretically grounded interaction between $\mathrm{PC}^{+}$and $\mathrm{EE}^{-}$is observed actually due to the manifestation of strongly expressed $\pi$-electronic interactions. The absorption spectra of this system evidenced about it. On Figure 5, spectrum 3 corresponds to the algebraic sum of the individual spectra of both dyes (additivity of light absorption is observed). 


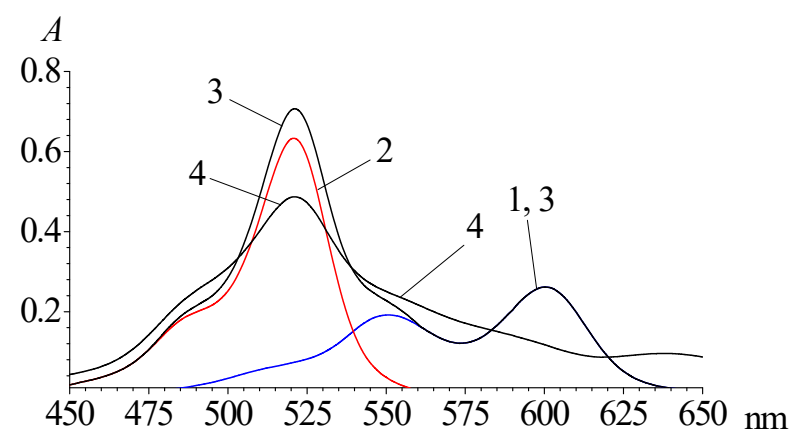

Figure 5. Absorption spectra of PC $\left(\mathrm{c}=5.52 \cdot 10^{-6} \mathrm{M}\right)$ with additions $\mathrm{EE}\left(\mathrm{c}=5.72 \cdot 10^{-6} \mathrm{M}\right)$. Spectrum: $1-\mathrm{PC} ; 2$ - EE; 3 - algebraic sum of 1 and 2 ("PC+EE" theor.); 4 experimental spectrum of the PC and EE mixture.

Spectrum 4 is experimentally obtained. Its difference from the total spectrum shows the existence of the formation of associates according to the equilibrium: $\mathrm{PC}^{+}+\mathrm{EE}^{-} \rightleftarrows$ $\mathrm{PC}^{+} \cdot \mathrm{EE}^{-}$(the structure of $\mathrm{PC}^{+} \cdot \mathrm{EE}^{-}$is presented on Figure 6; PM3 method; the interplanar distance along the axis 1 is $3.9-4.2$ angstrom).

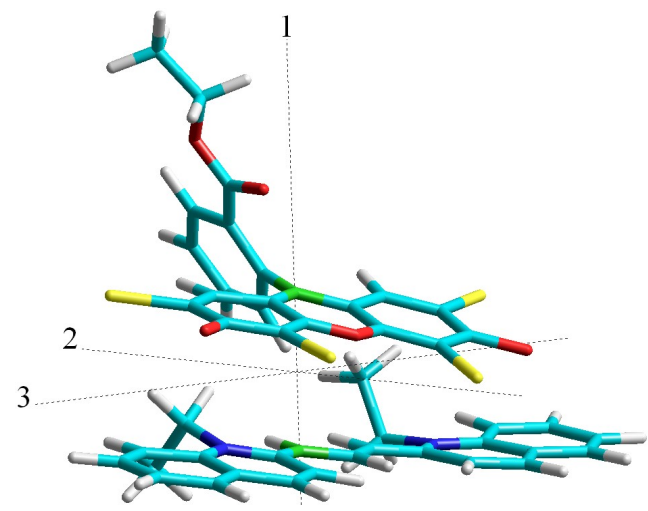

Figure 6. Optimized arrangement of dye ions in associate $\mathrm{PC}^{+} \cdot \mathrm{EE}^{-}\left(\mathrm{PC}^{+}\right.$is located at the bottom).

These spectrophotometric measurements indicate that the associates of $\mathrm{PC}^{+}$with $\mathrm{EE}^{-}$or $\mathrm{R}^{2} 20 \mathrm{C}^{-}$are quite stable (the value $\lg K_{\mathrm{as}}=$ $5.45 \pm 0,09$ is for $\mathrm{PC}^{+} \cdot \mathrm{EE}^{-}$associate).

It is possible to assume such scheme of interaction at the nonmicellar concentrations for the "PC-EE-TX" system: $\mathrm{PC}^{+} \cdot \mathrm{EE}^{-}+\mathrm{TX} \rightarrow$ $\mathrm{PC}^{+} \cdot \mathrm{TX}+\mathrm{EE}^{-}$. It corresponds to the release of $\mathrm{EE}^{-}$from associate. The contours of $\mathrm{EE}^{-}$ absorption spectra (5-7) are restored (Figure 7).

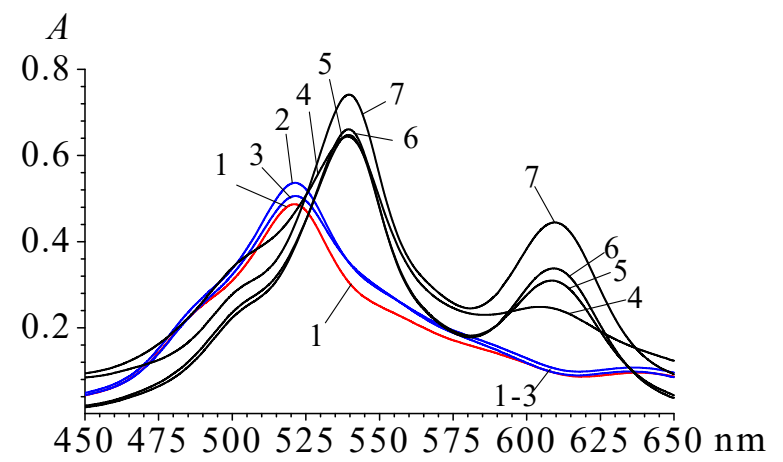

Figure 7. Absorption spectra of "PC-EE-TX" system. (c $\left.(\mathrm{PC})=5.52 \cdot 10^{-6} \mathrm{M}, \mathrm{c}(\mathrm{EE})=5.72 \cdot 10^{-6} \mathrm{M}\right)$ with $\mathrm{TX}$ additions: c (TX), M.10-4: $1-0 ; 2-1.01 ; 3-2.01 ; 4-$ $4.03 ; 5-6.04 ; 6-8.05 ; 7-10.1$.

Spectrum 1 corresponds to a mixture of dyes without surfactant; spectra 2, 3 show the interaction between PC and TX and the release of $\mathrm{EE}^{-}$(the maximum light absorption band of EE-is $520 \mathrm{~nm}$ ). In the micellar region of concentrations (spectra 4-7) there is a bathochromic shift of the maximum absorption of $\mathrm{EE}^{-}$(from $520 \mathrm{~nm}$ to $535 \mathrm{~nm}$ ) and the increase in absorption intensity with a bathochromic shift of the $\alpha$-band of PC absorption (from $600 \mathrm{~nm}$ to $610 \mathrm{~nm}$ ) due to solubilization of dyes by micelles of surfactant.

Analysis of the "PC-EE-SDS" system makes it possible to assert that its spectral changes are also clearly expressed (Figure 8). The scheme of interaction can be represented as substitution reaction in the before micellar region: $\mathrm{PC}^{+} \cdot \mathrm{EE}^{-}+\mathrm{SDS}^{-} \rightarrow \mathrm{PC}^{+} \cdot \mathrm{SDS}^{-}+\mathrm{EE}^{-}$. 


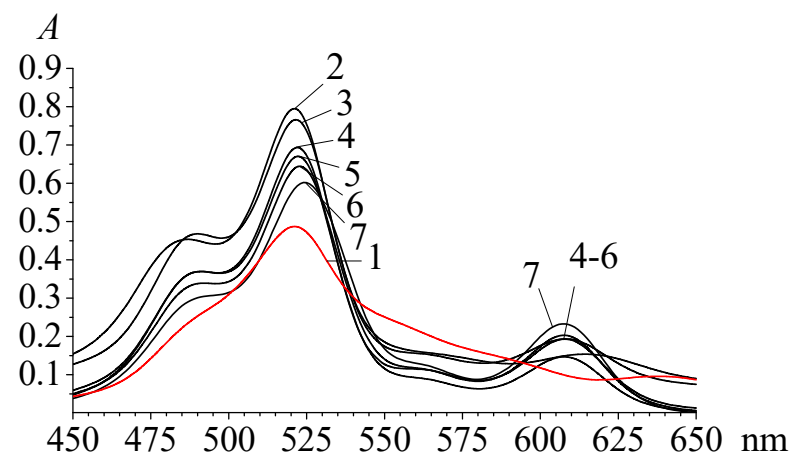

Figure 8. Absorption spectra of "PC-EE-SDS" system (c $\left.(\mathrm{PC})=5.52 \cdot 10^{-6} \mathrm{M}, \mathrm{c}(\mathrm{EE})=5.72 \cdot 10^{-6} \mathrm{M}\right), \mathrm{c}(\mathrm{SDS})$, $\mathrm{M} \cdot 10^{-3}: 1-0 ; 2-1.54 ; 3-6.15 ; 4-7.69 ; 5-8.45 ; 6-$ $9.22 ; 7-10.8$

The comparison of 2 and 3 spectra with the absorption spectrum of "PC-EE" without a surfactant (spectrum 1) indicates the presence of cation-anionic interactions in the before micellar region of concentrations, while the character of the spectra 4-7 indicates solubilization of dyes in the micelles of surfactant.

\section{Conclusions}

The experimental and calculated data of the interactions of cationic dye PC with anionic dyes EE, R200C, and ionic (CPB, SDS) and nonionic (TX) surfactant have been analyzed. It was established that the additives of alkylammonium salts to dyes do not influence on the absorption spectra at concentrations $10^{-6}-10^{-4} \mathrm{M}$. In contrast, ionic surfactants are capable of association with dyes. Such interactions are realized at nonmicellar concentrations according to the schemes:

$$
\begin{aligned}
& \mathrm{Ct}^{+}+\mathrm{SDS}^{-} \rightarrow \mathrm{Ct}^{+} \cdot \mathrm{SDS}^{-} \\
& \mathrm{CPB}^{+}+\mathrm{An}^{-} \rightarrow \mathrm{CPB}^{+} \cdot \mathrm{An}^{-} .
\end{aligned}
$$

Since the dye ion interacts with the surfactant counterion the dye associate destroys when the surfactant is added:

$$
\begin{aligned}
& \mathrm{Ct}^{+} \cdot \mathrm{An}^{-}+\mathrm{SDS}^{-} \rightarrow \mathrm{Ct}^{+} \cdot \mathrm{SDS}^{-}+\mathrm{An}^{-} \\
& \mathrm{Ct}^{+} \cdot \mathrm{An}^{-}+\mathrm{CPB}^{+} \rightarrow \mathrm{Ct}^{+}+\mathrm{CPB}^{+} \cdot \mathrm{An}^{-}
\end{aligned}
$$

The studied cation-anion interactions involving micellar surfactants and dyes can be represented regardless of the type of surfactant by the scheme:

$$
\mathrm{Ct}^{+}+\mathrm{An}^{-} \longrightarrow \underset{(\text { associate })}{\mathrm{Ct}^{+} \cdot \mathrm{An}^{-} \longrightarrow} \begin{gathered}
\text { surfactant } \\
\text { (micelles) }
\end{gathered}\left(\mathrm{Ct}^{+}\right)_{\text {surfactant }}+\left(\mathrm{An}^{-}\right)_{\text {surfactant }}
$$

Thus, the solubilization of the each dye is observed in micellar concentrations of surfactant. Semiempirical methods AM1 and PM3 determined the energy of cation-anionic associates "dye+dye" and associates "dye+surfactant" (the value of standard enthalpy of formation) for stoichiometry $1: 1$ which follows from spectrophotometric studies. It is noteworthy that in the absence of an explicit manifestation of non-specific (cation-anionic) interactions (for example, the "PC+TX" system), spectral changes still take place. AM1 and PM3 methods give consistent values of the determined values of the standard enthalpy of formation of molecules or dye associates. The energy utility of the interactions between the cation of the dye and the nonionic surfactant is confirmed by rather high (which essentially exaggerate the error of calculations) values of the standard enthalpies of formation. The combination of spectroscopic results with semiempirical simulations made it possible to 
analyze the thermodynamics and structural features of dyes and their associates with surfactants.

\section{References}

[1] Shapovalov SA. Processes of self-association of dyes in solutions. Riga: Academic Publishing of European Union, OmniScriptum Publishing group; 2018, pp. 1-122

[2] Rashid S, Usman M, Shahzad T, Saeed M, Haq AU, Ibrahim M, Siddiq M, Iram M. The differential spectroscopic investigation of partitioning of reactive dyes in micellar media of cationic surfactant, cetyl trimethylammonium bromide (CTAB). Zeitschrift fur Physikalische Chemie 2019; 233(2): 183-199

[3] Taj M, Khan MNN. Oppositely charged dye surfactant interactions: Extent and selectivity of ion pair formation. Journal of Molecular Liquids 2018; 266: 591596

[4] Olaseni SE, Osundiya MO, Oniya EO, Akeremale OA, Aboluwoye CO, Oyeneyin OE, Orunesajo A. Crystal violet partitioning in anionic surfactants micellar media: UV-visible spectroscopy study. International Journal of Thermodynamics 2018; 21(3): 136-142

[5] Mall C, Solanki PP. Spectrophotometric and conductometric studies of molecular interaction of brilliant cresyl blue with cationic, anionic and non-ionic surfactant in aqueous medium for application in photogalvanic cells for solar energy conversion and storage. Energy Reports 2018; 4: 23-30

[6] Ul Haq N, Usman M, Hussain A, Farooqi ZH, Saeed M, Hanif S, Irfan M, Siddiq M, Rana UA. Partitioning of reactive yellow 86 between aqueous and micellar media studied by differential absorption spectroscopy. Canadian Journal of Chemistry 2017; 95(6): 697-703

[7] Rub MA, Azum N, Asiri AM, Alfaifi SYM, Alharthi SS. Interaction between antidepressant drug and anionic surfactant in low concentration range in aqueous/salt/urea solution: A conductometric and fluorometric study. Journal of Molecular Liquids 2017; 227: $1-14$

[8] Wang W, Huang G, An C, Xin X, Zhang Y, Liu X. Transport behaviors of anionic azo dyes at interface between surfactant-modified flax shives and aqueous solution: Synchrotron infrared and adsorption studies. Applied Surface Science 2017; 405: 119-128

[9] Al-Omair NA. Investigation of interactions between sodium dodecyl sulfate and crystal violet in aqueous solution. Asian Journal of Chemistry 2017; 29(4): 911-916

[10] Göktürk S, Keskin G, Talman RYC, Çakır N. Spectroscopic and conductometric studies on the interactions of thionine with anionic and nonionic surfactants. Coloration Technology 2017; 133(5): 362368

[11] Wang N, Lin H, Zhu H. Study of the association behavior between bromophenol blue and octylphenol polyoxyethylene ether (10) in aqueous solution and the solubilization of bromophenol blue by micelles. Journal of Solution Chemistry 2016; 45(12): 1689-1700

[12] Ramadan MS, Nabil GM, Elmallah NM, Shaker AM. Spectral studies for interaction between methyl orange dye and cationic surfactants in acetonitrile as co-solvent with water. Asian Journal of Chemistry 2016; 28(2): 359-364

[13] Petcu AR, Rogozea EA, Lazar CA, Olteanu NL, Meghea A, Mihaly M. Specific interactions within micelle microenvironment in different charged dye/surfactant systems. Arabian Journal of Chemistry 2016; 9(1): 9-17

[14] Ghosh S, Mondal S, Das S, Biswas R. Spectroscopic investigation of interaction between crystal violet and various surfactants (cationic, anionic, nonionic and gemini) in aqueous solution. Fluid Phase Equilibria 2012; 332: 1-6

[15] Chernova RK, Kozlova LM, Shestopalova NB, Ryanova YuO. Test-methods determination organic 
substances in water environment. Izvestiya of Saratov University. Series: Chemistry, Biology, Ecology 2008; 2: $15-22$

[16] Kalenichenko KP. Opredelenie anionnyih poverhnostno-aktivnyih veschestv $\mathrm{s}$ pomoschyu indikatora $\mathrm{V}$ prirodnyih vodah. Journal of Water Chemistry and Technology 1987; 23(5): 107-110

[17] Shapovalov S, Ponomariov V. Interaction of dyes with cationic surfactants in solutions: Determination of critical micelle concentration. International Letters of Chemistry, Physics and Astronomy 2019;81:27-34

[18] Shapovalov SA, Ponomariov VK, inventors; V.N.Karazin KhNU, assignee. Method of spectrophotometric determination of the critical concentration of micelles of cationic surfactants in water. Ukraine patent 132448. 2019 Febr 2

[19] Abdine H, Belal F, Zoman N. Simple spectrophotometric determination of cinnarizine in its dosage forms. Farmaco 2002; 57(4): 267-271

[20] Sabate R, Estelrich J. Pinacyanol as effective probe of fibrillar beta-amyloid peptide: comparative study with Congo Red. Biopolymers 2003; 72(6): 455-463

[21] Patra N, Mandal B, Ghosh S. Spectroscopic studies on the interaction of dye and surface active ionic liquid Industrial \& Engineering Chemistry Research 2017; 56(36): 10044-10052

[22] Dutta R, Ghosh S, Banerjee P, Kundu S, Sarkar N. Micelle-vesicle-micelle transition in aqueous solution of anionic surfactant and cationic imidazolium surfactants: Alteration of the location of different fluorophores. Journal of Colloid and Interface Science 2017; 490: 762-773.

[23] Behera GB, Behera PK, Mishra BK. Self aggregation and behaviour in surfactants. Journal of Surface Science and Technology 2007; 23(1-2): 1-31

[24] HyperChem 7 Release [Internet]. USA: Hypercube, Inc; C 2002. HyperChem getting started [about 2170 p.] Available from: http://www.chemistrysoftware.com/pdf/Hyperchem_full_manual.pdf
[25] Astakhov SA, Baranov VI, Gribov LA. Theory and methods of computational vibronic spectroscopy. New York: Nova Science Publishers; 2008, $83 \mathrm{P}$.

[26] Huang X, Yang J, Zhang W, Zhang Zh, An Z. Determination of the CMC of Cationic Surfactants. Journal of Chemical Education 1999; 76(1): 93-94

[27] Hait SK, Moulik SP. Determination of critical micelle concentration (CMC) of nonionic surfactants by donor-acceptor interaction with lodine and correlation of CMC with hydrophile-lipophile balance and other parameters of the surfactants. Journal of Surfactants and Detergents 2001; 4: 303-309

[28] Obukhova EN, Mchedlov-Petrossyan NO, Vodolazkaya NA, Patsenker LD, Doroshenko AO, Marynin AI, Krasovitskii BM. Absorption, fluorescence, and acid-base equilibria of rhodamines in micellar media of sodium dodecyl sulfate. Spectrochimica Acta Part A: Molecular and Biomolecular Spectroscopy 2017; 170: $138-144$

[29] Abdul Motin MdA, Hafiz Mia MA, Nasimul Islam IAKM. Thermodynamic properties of sodium dodecyl sulfate aqueous solutions with methanol, ethanol, $n$-propanol and iso-propanol at different temperatures. Journal of Saudi Chemical Society 2015; 19(2): $172-180$ 